\title{
El enfoque sistemático en Educación Especial
}

\section{José Luis Ortega *}

\author{
Escuela Especializada de Ntra. Sra. de Meritxell
}

\section{EL ENFOQUE SISTEMATICO EN EDUCACION ESPECIAL}

El término «enfoque sistemático» (por el cual podemos traducir la denominación inglesa quizás más adecuada de «System Apprach») parece que sea usada habitualmente en dos sentidos distintos. El primero implica el esfuerzo ordenado y metódico para el diseño, implantación y evaluación de procesos educativos (Howe, 1980). Esta acepción conlleva únicamente la implicación de que estamos tratando con modelos consistentes en etapas ordenadas para la organización de la práctica educativa. El modelo que será presentado más adelante se originó en un esfuerzo para tal enfoque sistemático. Este sentido no comporta como tal conexión alguna teórico-particular $y$, por este mismo motivo, no confiere al enfoque sistemático valor alguno más allá del que resulta de su eficacia operacional, aunque, ciertamente la eficacia es o debería ser el criterio último al cual habrian de someterse todas las condiciones y teorizaciones restantes.

En otro sentido, podemos entender que "enfoque sistemático» connota la idea de la educación como sistema y relacionarlo de esta forma con la Teoría General de Sistemas (Bertalanffy, I968). Un sistema puede ser caracterizado como un conjunto de elementos interconectados mediante relaciones específicas que tiene un propósito o función definidos. Dos de las propiedades de los sistemas definidos así resultan especialmente relevantes por el enfoque sistemático según el sentido argumentado en el párrafo precedente.

Inicialmente, un sistema evoluciona en dirección a la diferenciación, por la cual hay que entender la sustitución de los modelos globales y más difusos por funciones más especializadas (Katz y Kahn, 1966). En el caso de los sistemas educativos esto significa progreso hacia una mayor complejidad en los modelos y unas tecnologías más eficientes para la consecución de los objetivos especificados. Lo que resulta importante es que a cada cambio en una parte determinada del sistema corresponden cambios obligados en las otras partes, necesarios para la conservación del propósito o finalidad del sistema. De igual forma, toda decisión o modificación en cualquier etápa del proceso de diseño sistemático implicará a las otras, a través de un mecanismo de feed-back que se encuentra presente en la mayor parte de modelos instructivos (Glasser, I960; Kaufman, 1973; Fernández, Sarramona y Tarín, 1977).

En segundo lúgar, un sistema existe siempre en el contexto de sistemas de más alto nivel e incluye sistemas de menor rango, todos los cuales han de ser considerados al planificar una intervención (Sundberg, Tyler y Taplin, 1973). Miller (197I) describe siete niveles relativos a los sitemas u organismos vivos: celular, orgánico, organísmico, grupal, organizacional, societal y supranacional. Aunque todos estos niveles y quizás más puedan resultar útiles en contextos particulares, en educación especial y en el trabajo

\footnotetext{
* Dirección del autor: Escuela Especializada de Nuestra Señora de Meritxell, Valle de Andorra.
} 
escolar parece conveniente restringir algo el número de los mismos. Así, habria un nivel correspondiente al sistema biológico, que incluiría todas aquellas variables que son responsabilidad habitualmente del médico y que son tratadas mediante acciones farmacológicas, con el objetivo de dejar al organismo en condiciones óptimas para la entrada en los programas de aprendizaje del nivel siguiente. Un nivel conductual correspondería al comportamiento individual de sujetos particulares. A continuación, el nivel de pequeño grupo trataria al menos dos unidades fundamentales: Compañeros y familia. Finalmente, otro nivel corresponderia al sistema social más general, al cual concernirian actitudes sociales generales, directrices gubernativas o ministeriales, leyes, etc. Quizá alguien podría pensar que el enfoque sistemático trataría predominantemente los pequeños grupos correspondientes al conjunto de alumnos de un aula, pero el movimiento en favor de una enseñanza individualizada nos recuerda la necesidad de tomar en consideración los sistemas de comportamiento individual, $y$ autores como Kaufman (1979, 1980) y Kaufman y Stone (1979) insisten ya en la necesidad de considerar igualmente los contextos culturales y sociales de las prácticas educativas.

Conviene recordar que los distintos niveles de sistemas pueden requerir distintas tecnologías e implican a diferentes profesionales (psicólogos, médicos, educadores, asistentes sociales, etc.) Un diseño concreto puede precisar la intervención coordinada de todas las vías de aproximación requeridas e implicar asi toda la complejidad del trabajo de equipo multidisciplinario.

Las dos acepciones que acabamos de comentar están en realidad estrechamente relacionadas. Resulta importante disponer de modelos de trabajo que sean suficientemente comprensivos y flexibles para incluir la complejidad inherente a los sistemas educativos y de la cual la teoría general de sistemas nos instruye, sin olvidar que éstos habrán de ser aplicados en unas condiciones que sólo excepcionalmente serán óptimas en cuanto se refiere al tiempo de dedicación posible por parte del educador o responsable de la programación, la posibilidad realmente libre de .elección entre alternativas, a menudo restringidas por constreñimientos estructurales, etc.

Comentaré en primer lugar, en el presente artículo, algunas características de aquello que yo percibo como división y distanciamiento entre las tradiciones de trabajo que podríamos denominar "tecnologia educativa» y "modificación de conducta», ambas con un fuerte, aunque limitado, arraigo entre nosotros, e intentaré defender la necesidad de una aproximación. Esta parte introductoria me ha parecido necesaria dado que el resto del presente trabajo debería interesar, en la medida qué haya acertado en su redacción, a «tecnólogos educativos» y «modificadores de conducta» a la vez.

Seguidamente presentaré algunos modelos anteriores que me parecen fundamentales e inmediatamente entraré, de una forma un tanto somera, en algunas peculiaridades de la educación especial relevantes a un enfoque sistemático en este terreno para pasar finalmente a la exposición de nuestro modelo.

La única aclaración que resulta precisa es la de que he intentado explicar no sólo el sentido y la técnica de cada etapa, sino también como ambos pueden, y a mí entender deberian, relacionarse con el cuerpo de conocimientos provisto por la psicología experimental. Sugerir, y en el mejor de los casos justificar esta necesidad de relación es propiamente la finalidad principal del presente trabajo.

\section{MODIFICACION DE CONDUCTA Y ENFOQUE SISTEMATICO}

Inicialmente, parecería que modificación de conducta y enfoque sistemático de la enseñanza tendrian un punto importante de coincidencia en base a su participación común en una voluntad crítica, experimental y de autocontrol manifestada tanto en las literaturas respectivas como en las prácticas observadas. A pesar de ello quisiera argumentar aquí que eso no es exactamente asi en la realidad. 
En obras tan clásicas como la de Kaufman (1973) o tan completas en otros aspectos como la de nuestros autores Fernández Sarramona y Tarín (1977), hay cierta imprecisión conceptual en lo referente a los principios de la psicología del aprendizaje, que a menudo se limita a la descripción de las famosas «tendencias», "conductista», "gestáltica», "psicoanalítica», etc.

La modificación de conducta ha aportado una precisión y exigencia de control y también un conjunto importante de técnicas eficaces a la práctica educativa. $\mathrm{Ha}$ olvidado, empero, la importancia de los modelos más complejos de la tecnología educativa y ha tenido propensión a ignorar las aportaciones de la psicologia experimental más allá de las teorias del aprendizaje (condicionamientos respondiente y operante principalmente).

En resumen, la tecnología educativa ha tenido tendencia a olvidar o ha entendido mal la psicología experimental, mientras que la modificación de conducta se ha inclinado a reducir su campo de aplicación al tipo de problemas que eran más fácilmente reducibles al tipo de análisis en términos de paradigma operante que le ha sido más propio. La ignorancia de los modelos más complejos de tecnología educativa le ha facilitado esta posición limitada y en cierto sentido reduccionista.

Que esta afirmación no es exagerada lo demuestra el escaso número de referencias mutuas entre los autores de ambas líneas, fácilmente comprobable repasando revistas tan significativas como el "Journal of Applied Behavior Analysis" o la "Programed Learning and Educational Technology».

\section{EL MODELO}

El modelo que será expuesto a continuación intenta, en la perspectiva de una confluencia entre ambas tendencias, cumplir dos finalidades:

En primer lugar proveer a los educadores de un modelo útil de trabajo en su práctica cotidiana. Una consideración se hace necesaria para precisar el sentido de esta pretendida utilidad: queja muy frecuente es la de la falta de tiempo para cumplir con todo rigor las condiciones $y$ criterios impuestos por distintos modelos y concretamente por el presente. Conviene decir a este respeto, que el modelo puede ser parcialmente aplicado, manteniendo aún un nivel de rigor suficiente. Por ejemplo, la definición operacional de objetivos es imprescindible, mientras que otras partes del modelo solamente son altamente deseables o constituyen recursos tecnológicos o conceptuales que pueden ser utilizados o no. Por otro lado, renunciar a algunos apartados del modelo (no necesariamente de éstc, estos apartados son comunes a todos los modelos de diseño sistemático de programas) implica simplemente la renuncia a un nivel superior de eficacia.

En segundo lugar, quiere constituir un instrumento para la clarificación y sistematización de las oportunidades de interacción entre psicologia y práctica educativa. En efecto, y como se verá en la exposición detallada de los apartados del modelo, cada uno de ellos supone un conjunto específico de oportunidades diferentes para esta interacción. El modelo en conjunto requiere la participación de la psicología experimental más allá de los paradigmas de condicionamiento, desde teorias de procesamiento de la información hasta motivación o psicología diferencial.

De esta forma, es posible que empiece a debilitarse un cierto aislamiento entre tendencias que si, posiblemente ha sido entre nosotros más rígido, ha existido y existe tambièn en la literatura internacional.

\section{ANTECEDENTES Y REVISION DE OTROS MODELOS}

El modelo de Glasser. El modelo básico del cual puede decirse que derivan en mayor o menor medida la mayoría de elaboraciones posteriores fue propuesto por Glasser (1964) y puede ser representado por el esquema siguiente: 
GrAFICO 1

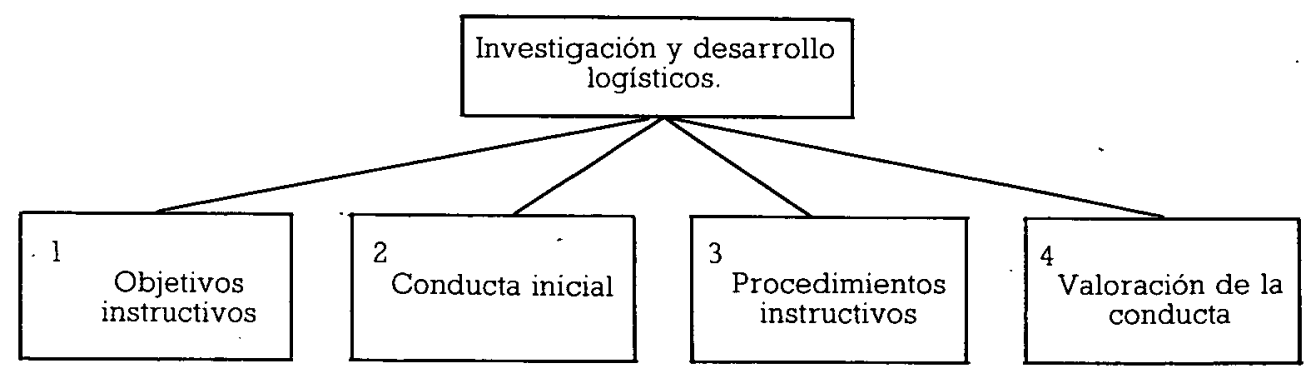

\section{Modelo de Glasser}

Observamos que, en efecto, estas etapas son las más básicas y fundamentales del proceso instructivo. La estructura relativamente simple del modelo no impide que contenga conceptos importantes:

I. La definición de objetivos como paso inicial del proceso de diseño.

2. La necesidad de una evaluación inicial para verificar el nivel de entrada de los niños.

3. Un mecanismo de feed-back que enlaza entre si todas las etapas.

El modelo de Kaufman. En una obra importante, traducida además relativamente pronto al castellano, Kaufman (1973) propuso un modelo de ámbito más comprensivo que el de Glasser y que incluye las siguientes etapas:

GrAFICO 2

REVISION

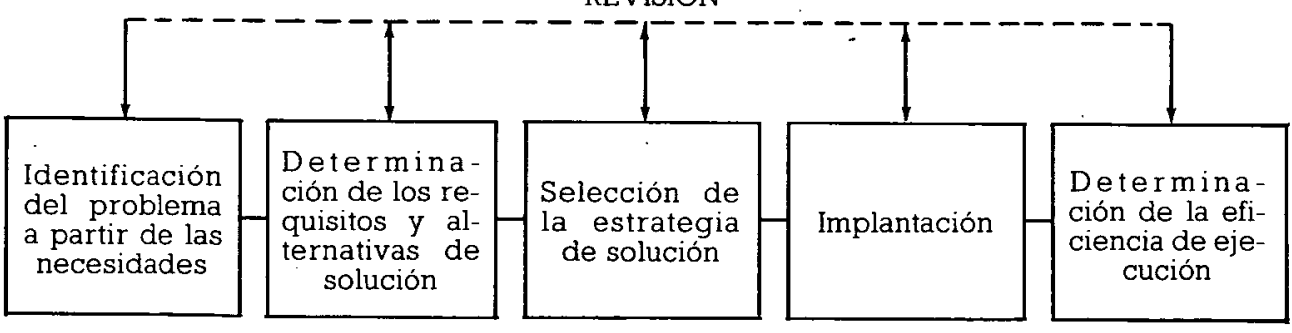

\section{Modelo de Kaufman}

Este modelo fue recogido entre nosotros por Tarín y Llacuna (1976) los cuales hicieron una exposición que a mi criterio supera en algunos puntos la del propio Kaufman. Además del desarrollo de ideas que podian sernos ya conocidas a través de modelos anteriores como el de Glasser, la idea más destacable y cuya importancia no puede ser desdeñada es la de la concepción de la «identificación» de necesidades como noción y etapa independiente y previa a la definición de objetivos. Sin duda, otras nociones son más ambiguas y de difícil aplicación en la práctica y en particular el desglose de la «determinación de los requisitos $\mathrm{y}^{\mathrm{a}}$ alternativas de solución» en análisis de funciones, misiones y tareas resulta confuso y para mí inaplicable en el contexto del diseño de programas educativos. 
Modelo de Fernández, Sarramona y Tarin. Partiendo de los modelos anteriores y de otros, Fernández, Sarramona y Tarin (1977) propusieron un modelo muy completo y aplicable que tiene el mérito, además, de desglosar el "procedimicntoi en una serie de apartados de obvia identidad propia que merece, por tanto, una atención específica. El esquema que estos autores proponen es el siguiente:

Gririco 3

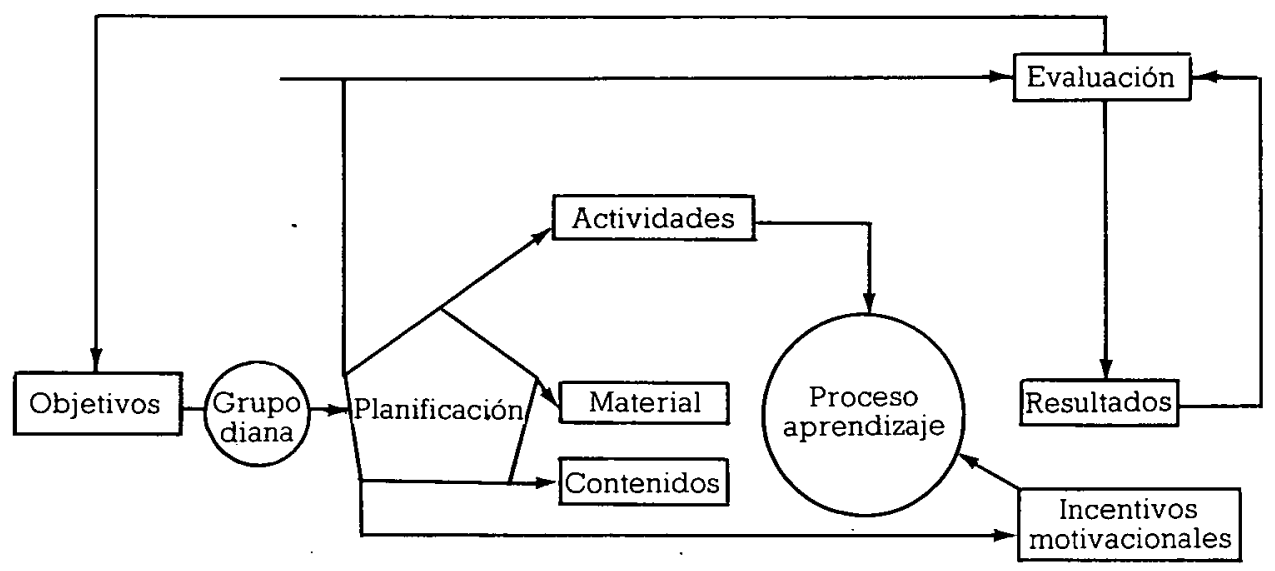

Modelo de Fernández, Serramona y Tarín.

Este es, quizás, el modelo a la vez más comprensivo y aplicable. Sus limitaciones pueden reducirse a la falta de una etapa de identificación de necesidades y a la mala definición y ambigüedad de los postulados psicológicos. Finalmente, una aplicación en el campo de la educación especial requiere seguramente una serie de adaptaciones peculiares.

\section{EL ENFOQUE SISTEMATICO APLICADO A LA EDUCACION ESPECIAL}

Es preciso afirmar que las similitudes en la aplicación del enfoque sistemático a la educación normal y a la especial son más y más fundamentales que las diferencias. Los aspectos en que más se diferencian ambas aplicaciones podrian ser los siguientes:

I. Diferente nivel de complejidad de los objetivos y de minuciosidad y detalle necesarios en la programación. Escogido un tema relevante a enseñar, es muy probable que el desglose de los objetivos sea distinto en la educación especial y en la normal. Un criterio importante que ayuda a esta diferenciación es que en educación especial, al menos en algunos niveles, los objetivos van unidos siempre a conocimientos que el alumno ha de poder utilizar. En educación normal, son muy importantes los conocimientos que el alumno ha de tener, aunque su uso práctico no sea claro. Por ejemplo, a un mismo nivel curricular, en un caso se pueden estar trabajando objetivos de numeración como lectura de cifras, cuenta de objetos, sumas $n+1$, etc., mientras que en el otro estarian incluidos como nociones de unidad y decena, de base $\mathbf{I}$, 2 , etc. A pesar de lo que acabo de exponer, creo que el terreno de la diferenciación y adecuación de objetivos a alumnos de distintos niveles intelectuales o en general de características especificas queda todavía y desgraciadamente insuficientemente explorado, cuando es, parece, ciertamente de importancia fundamental.

Si los objetivos derivados de un mismo contenido pueden variar en el caso de la 
educación especial y de la normal, igual sucede con el análisis de tareas y posterior secuenciación. Si no el único, posiblemente uno de los más potentes y experimentados (o al menos practicados) procedimientos para aumentar la eficacia de los programas educativos en la educación especial sea el progresivo desdoblamiento de los objetivos en pasos más fáciles y posiblemente trabajables con principios de aprendizaje más bajos (si partimos de algún tipo de jerarquia de condiciones de aprendizaje como la muy conocida de Gagné, 1970). Probablementé, la conducción de este desglose hasta iguales niveles en programas de educación normal tendria efectos ralentizadores $y$ desmotivadores (este es uno de los fundamentos principales de la existencia de distintos tipos de programas usados habitualmente en textos: lineales, ramificados, etcétera).

2. La distinta practicabilidad y/o idoneidạd de métodos y procedimientos. En educación normal hay un amplio abanico de posibilidades de elección en lo referente a la forma de acto didáctico: clase magistral, trabajo en pequeño grupo, discusión y conclusiones colectivas, uso de bibliotecas, textos programados, etcétera. Además existen las distintas técnicas de trabajo individual o colectivo como son recensiones, apuntes, esquemas, archivos, etcétera. En educación especial, a pesar de que sería importante verificar los límites reales de elección, estas posibilidades no pueden ser utilizadas en muchos casos $\mathrm{y}$ en otros únicamente en forma restringida. El trabajo individualizado es la norma, o al menos la norma ideal a la cual se tiende $y$, aunque esta actitud pueda cambiar, es obvio que la proporción entre trabajo individual y, por ejemplo, clase colectiva o trabajo en grupo será siempre muy diferente a la posible en educación normal.

Como antes he sugerido, no está perfectamente claro hasta qué punto estas diferencias derivan de tradiciones de trabajo diferentes o de constreñimientos reales. Mi opinión es que estos constreñimientos existen y son fundamentales, pero que una esmerada investigación tendría que ir escogiéndolos y verificándolos.

\section{NUESTRO MODELO}

El modelo que será presentado a continuación se originó históricamente en las discusiones del entonces embrionario "Grupo de Investigación en Educación Especial», en las que confluyeron distintas tendencias, dentro, empero, del marco que puede denominarse línea «sistemática». El resto del presente trabajo pretende un desarrollo teórico de cada uno de los componentes del modelo, además de una descripción de las principales técnicas relativas a cada uno de ellos. Esto parece muy necesario, ya que la elaboración del modelo hasta este momento únicamente contiene una definición somera de los componentes.

\section{Identificación de necesidades}

La identificación de necesidades tendría que ser el punto de partida ordinario de cualquier práctica educativa. Desgraciadamente, su importancia no está suficientemente reconocida. El objetivo del proceso de identificación de necesidades es el de seleccionar discrepancias verificables entre lo que "existe en este momento" y lo que "debería ser» (Kauffman, 1973). En cierto sentido, una necesidad es semejante a un objetivo, ya que ambos se refieren a resultados observables y medibles de la intervención; la diferencia radica más bien en el nivel de detalle que en el concepto. Así, por ejemplo, una necesidad podria ser la de que un niño pudiese leer las mismas letras que sus compañeros mientras que el objetivo consistiria en la adquisición de las conductas requeridas ante los signos a, e, etcétera. Kauffman (1973) insiste que las diferencias que las necesidades expresen consisten en discrepancias mensurables. En la práctica, sin embargo, resulta más natural que las necesidades se refieran a conductas observables y que indiquen solamente la dirección del cambio, incremento o disminución, mientras que el criterio de mensurabilidad y plena operacionalidad quede para la definición de objetivos.

La identificación de necesidades proporciona la justificación, direccionalidad y criterio último de evaluación del con- 
junto del proceso educativo. Incorpora en el modelo de diseño instructivo algo muy similar a la preocupación por la "funcionalidad» tan profundamente presente en autores de la línea de modificación de conducta tan importantes como Küzzlof (1974) y Ribes Iniesta (1972). La idea es que ya no podemos continuar actuando sobre los niños sin saber o sin preocuparnos de la importancia que un objetivo particular tiene para un niño concreto en su entorno propio, dentro del cual las conductas enseñadas habrán de resultar útiles, y el cual, en último término, las reforzará y mantendrá o extinguirá y determinará, por tanto, su generalización y mantenimiento.

Existen diversos modelos para la identificación de necesidades. Cuatro de los más conocidos son comparados por Trinby (1979). El modelo de Kauffman (1973, 1975), que es quizá el más comprensivo, postula que el análisis de necesidades ha de tener en consideración al menos tres partes implicadas: educadores, educandos y comunidad. I.as necesidades de los educandos resultan de su situación biológica (por ejemplo: trastornos, parálisis cerebral, epilepsia, etcetera), su nivel de desarrollo (retraso, específico o general) y también, y no en último lugar, de las necesidades y preocupaciones expresadas por ellos.

Actualmente asistimos a un cambio de actitud que se aparta de los instrumentos de evaluación más tradicionales como son los tests psicométricos y los diagnósticos y étiologias médicos y se acerca a procedimienros menos normativos y más directamente funcionales: tests referidos a criterios, como, por ejemplo, el U. P. A. S. (White et al., 1978), registros de línea base (Kozloff, 1974) de observación directa. Yo diría que los dos estilos son complementarios y no antagónicos y que la información aportada por todos ellos no puede ser ignorada.

- En segundo lugar, el conocimiento a disposición de los educadores, su ideología, disponibilidad y capacidad conforman también un conjunto de necesidades. Es muy probable que dos educadores diferentes, según las características de los factores que acabamos de nombrar que les sean propias, verán de forma distinta las prioridades en las necesidades e incluso podrán discrepar en la existencia de ciertas necesidades. Por ejemplo, un educador puede considerar que un niño debe superar el nivel preoperatorio de desarrollo cognitivo para llegar a la operatividad concreta, mientras que otro preferirá concentrarse en necesidades referidas a curricullums académicos, etcétera.

Finalmente, la comunidad impone y determina unas necesidades a través de leyes generales de educación, requerimientos, etcétera, y los padres pueden y han de expresar su opinión sobre la educación de sus hijos, opinión que debe ser escuchada y considerada.

Uno de los trabajos más importantes y no precisamente más fáciles del educador o responsable de la programación es la de la conciliación entre las diferentes $y$, a veces, contradictorias necesidades expresadas por los distintos estamentos. Cuestionarios; reuniones y entrevistas sólo son algunas de las técnicas que habrán de ser utilizadas en este proceso.

\section{Definición de objetivos}

Una correcta definición de objetivos es el secreto sobre el cual descansa la eficacia de todo programa de enseñanza. Es cierto que muchos educadores tienen un nivel aceptable de eficacia sin utilizar objetivos operacionalmente definidos y también es cierto que, a veces, no es posible llegar a definir de esta forma la totalidad del resultado apetecido de la enseñanza, por razones de complejidad, tiempo o tecnología. No obstante la diferencia entre los programas, cuyos objetivos hayan sido definidos operacionalmente y los otros, resulta manifiesta a todos los que han experimentado ambas formas de trabajo, es determinante de la comunicabilidad de las razones de esta eficacia y, en cualquier caso, y en lo que pueda implicar de decisión ideológica y no exclusivamente de eficacia práctica, es la línea en la que se incluye la intencionalidad del presente trabajo.

Verdaderamente ha sido una suerte el haber podido disponer tempranamente 
de la formulación excepcionalmente clara y didáctica de un autor como Mager (1962), el cual postuló los requisitos formales de una conveniente definición de objetivos.

Como es sabido, estos criterios son los de definición de la respuesta del sujeto en términos conductuales, la especificación de las condiciones en las que esta respuesta habrá de ser emitida y la determinación de los criterios para aceptar como logrado el objetivo.

a) Definición de la respuesta en términos conductuales. Hay expresiones y verbos que indican acrividades que permanecen en el interior del sujeto y que no pueden ser, por tanto, directamente observadas ni legítimamente inferidas. Otras, en cambio, hacen referencia explícita a acciones observables del sujeto. Esta última característica de posibilidad de observación objetiva es condición necesaria y determinante de una buena definición, que llamamos operacional del objetivo. A guisa de muestra podemos dar como ejemplos de verbos operacionales los siguientes: escribir, dibujar, seleccionar, resolver, enumerar, etcétera. En cambio, no son operacionales verbos como: saber, comprender, creer, apreciar, tener conciencia de, etcétera.

b) Condiciones de emisión de la respuesta. Una respuesta se da șiempre frente a determinados estimulos o controles verbales y físicos y con una ayuda material también determinada. Según las condiciones, una misma respuesta se vuelve más o menos concreta y sobre todo más o menos difícil. No es igual escribir en un papel pautado que en papel blanco, ni resolver problemas con calculadoras o sin ellas. Sin esta especificación de condiciones es obvia la definición de la respuesta, por precisión y, por tanto, por operacionalidad.

c) Criterios de corrección de la respuesta. No siempre un educador pretende la perfección en la respuesta correspondiente a un objetivo determinado $y$, a veces, la corrección de una respuesta únicamente puede entenderse en relación a un margen de error aceptable desde la perspectiva del sentido o funcionalidad del programa. Este es el último criterio que complementa y completa necesariamente la definición de objetivos.

Una forma práctica de definir los criterios de aceptación de un objetivo es la propuesta por Bender y Valletutti (1976). Estos autores enuncian un nivel de ejecución requerido (n. e. r.) y unas observaciones recomendables (o. r.).

Los objetivos, hemos visto, han de ser definidos operacionalmente. Ahora bien, este es un criterio formal y no de contenido. A este último nivel se sitúan algunos intentos de establecimiento de categorías de objetivos que tendrían una intención taxonómica.

Bloom y su equipo (1971) son los autores de una taxonomía que ha llegado a ser clásica. Distribuyen los objetivos educativos en tres dominios: cognoscitivo, afectivo y psicomotor. Cada dominio tiene unas categorías y subcategorias de objetivos para su ordenación. Asi, el dominio cognoscitivo se compone de seis categorías: conocimiento, comprensión, aplicación, análisis, sintesis y evaluación; el dominio afectivo incluye, a su vez, los siguientes: recibir, responder, valorizar, organización y caracterización para un valor o complejo de valores; finalmente, los objetivos del dominio psicomotor pueden jerarquizarse de la siguiente forma: percepción, propensión, respuesta dirigida, estructuración y operación externa compleja.

El problema principal de esta taxonomía y de otras muchas es el de mala definición y poca operacionalidad de cada categoría, lo cual hace que en la práctica resulte dificil de seguir. No obstante, tiene el valor de recordarnos que el problema de una taxonomía de objetivos existe, es importante y no está aún resuelto.

Gagné y Board (1978) han propuesto recientemente un nuevo modelo que distingue cinco tipos de resultados del aprendizaje: habilidades intelectuales, información verbal, habilidades motoras, estrate- 
gias cognoscitivas y actitudes. Estas cinco variedades de resultados del aprendizaje han de ser valorados en términos de cantidad y calidad y pueden serlo a través de procedimientos más o menos directos. Este modelo parece más útil en el sentido que las categorias tienen una definición relativamente precisa y parecen intuitivamente corresponder, en efecto, a diferencias reales entre objetivos. Pero el problema es que el modelo no deja de producir una cierta sensación de arbitrariedad en la selección $y$ de no exhaustividad en la clasificación. Es un modelo tentador que si bien es cirto que supone un cierto adelanto, no deja de requerir también un ulterior desarrollo.

Una clasificación de cariz más práctico y que creo merece una cièrta atención es la de Tarín y ILlacuna ( 1976 ). Tales autores distinguen cinco etapas sucesivas de adquisición de información que van desde un origen muy elemental a los grados más complejos de información: información terminológica, información de hechos concretos, información de procesos lógicos, información de aplicación e información de valoraciones.

Como conclusión puede decirse que la corrección de la forma de los objetivos tiene una formulación clara y univoca que corresponde a lo que recibe la denominación de definición operacional de objetivos. Contrariamente, los problemas de la taxonomía de los objetivos, que hace referencia a su contenido, queda todavía por resolver y sólo disponemos de tentativas sugeridoras que están lejos de pretender o ser definitivas.

Finalmente, es necesario insistir en que los objetivos han de desarrollarse, en sus caracteristicas formales y de contenido, a partir de las necesidades identificadas, tal y como se anunciaba en el apartado precedente. Si, como decía Mager, una mala definición de objetivos no nos permite saber dónde vamos, si estamos avanzando o no y cuándo habremos llegado, una despreocupación por las necesidades nos puede hacer saber dónde vamos, que nos estamos acercando al fin deseado y que hemos llegado y desconocer por qué hemos tenido que ir.

\section{Análisis de tareas}

El análisis de tareas es el proceso por el cual un objetivo determinado es analizado en sus componentes últimos a efectos de programación de la enseñanza. El análisis de tareas se puede aplicar a distintos niveles y, de esta forma, es posible ver al menos un cierto paralelismo entre el proceso de secuenciación de objetivos y el análisis de tareas propiamente dicho de cada uno de los objetivos.

Resnick y Ford (1978) arguyen la utilidad de distinguir entre análisis de tareas empírico y racional. Advirtiendo que, en la práctica, estos dos tipos son dificilmente mantenibles en estricta separación, estos autores introducen una distinción que resulta particularmente clarificadora.

$\mathrm{El}$ análisis de tareas racional, o, mejor dicho, el polo racional, en el análisis de tareas, pretende la descripción «ideal» $\mathrm{de}$ formas de ejecución de trabajos determinados, a menudo altamente eficaces, pero no necesariamente correspondientes a las formas de actuación de sujetos humanos reales. Una línea de trabajo actualmente importante basada en el análisis de trabajos racional es la de investigación en inteligencia artificial, que tan fecunda está resultando para la psicología cognitiva (Simon, 1979).

Además tenemos el análisis de tareas empírico, el cual busca la interpretación de los datos provinentes de los registros (errores, latencias, movimientos de ojos o manos, etcétera) tomados en sujetos humanos mientras realizaban distintos trabajos y la descripción o creación de un modelo que dé cuenta de los datos observados.

Los intentos de desarrollar unos modelos generales para el análisis de tareas han sido numerosos. No obstante, en el marco de esta exposición sólo serán tratados unos cuantos, seleccionados no tanto para proporcionar una representación exhaustiva del terreno como por el valor histórico o heuristico que, en mi opinión personal y a veces experiencia práctica con ellos, puedan tener.

Uno de los modelos más importantes de que disponemos fue propuesto por 


\section{$\mathrm{GRÁFICO}_{4}$}

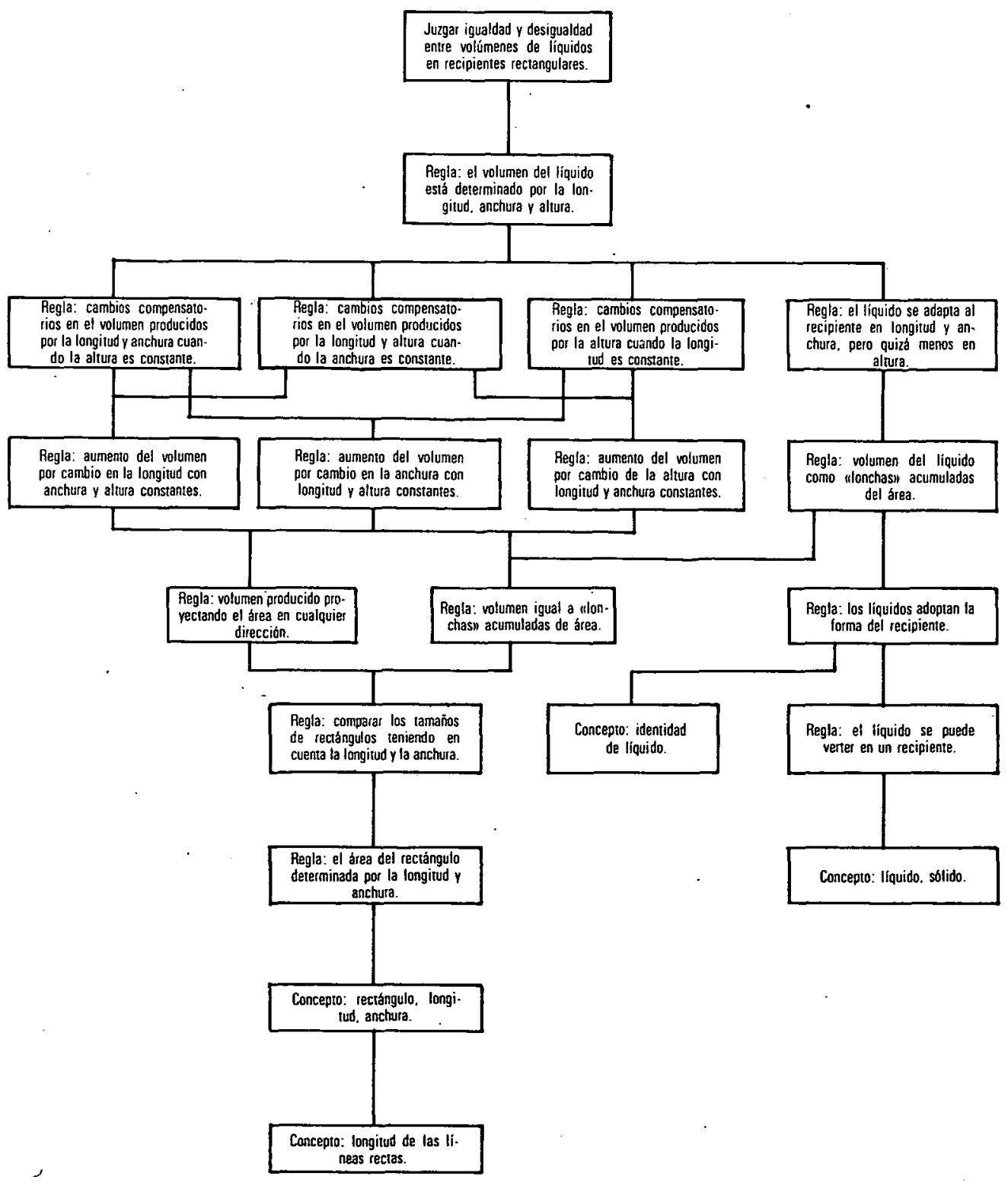


Gagné (1970, 1978) y desde su presentación ha sido probablemente el intento más serio de describir una jerarquía de secuencias útiles para el análisis de tareas complejas, que haya intentado no salirse del marco de las teorias del aprendizaje. El modelo postula ocho tipos diferentes de condiciones de aprendizaje de dificultad creciente, de forma que los niveles inferiores son indispensables para la consecución de los objetivos de categorias superiores. Estas categorias son: reacción ante una señal, estímulo/respuesta, encadenamicnto, asociación verbal, discriminación múltiple, conceptos, principios y resolución de problemas. Este modelo es fácil y claro de aplicar hasta el nivel de conceptos. Personalmente he encontrado siempre los niveles de principios y problemas más ambiguos y de aplicación más arbitraria.

El propio Gagné (1978) propone, a guisa de ejemplo, un análisis de tareas de acuerdo con el modelo y aplicado a una tarea compleja y teóricamente significativa como es la conservación de los líquidos, que presentamos en la hoja siguiente, a fin de que el lector se pueda formar una, idea de la aplicación del modelo (es necesario remarcar que Gagné propone este análisis de tareas como posible y no como seguro, cosa que únicamente podría afirmarse después de un proceso de experimentación).

Hemos dicho que Gagné ha sido de los pocos en enfrentarse con tareas complejas, y reivindicadas por otras posiciones teóricas en defensa propia, intentando no salir del marco de las teorias del aprendizaje. Usualmente, sin embargo, los diseñadores de programas que no han querido salir de este marco, es decir, de la interpretación de la conducta en términos de los paradigmas de condicionamiento clásico y operante, han actuado subdividiendo los trabajos en pasos tan pequenos como fuera necesario para que pudiesen ser presumiblemente aprendidos mediante las operaciones prácticas derivadas de estos paradigmas, y éstas son exclusivamente el control de estímulos y el control de contingencias. Eso implica en la práctica un reduccionismo a los niveles por debajo de conceptos del modelo de Gagné y especialmente un énfasis en los procesos de discriminación entre estímulos. Los modelos que siguen plantean algunos de estos problemas, pero si los resuelven o no es aún una cuestión sin resolver.

Otra posición teórica importante que ha dado lugar a intentos propios de programación de aprendizajes es la de la psicologia operatoria. Sin intentar siquiera describir las bases de las posiciones de Piaget y sus colaboradores y seguidores, podemos recoger los principios relevantes para la programación que de ellos se derivan, tal y como son expuestos por Moreno y Sastre (1971) y por Inhelder, Sinclair y Bovet (1974). Estos autores coinciden en remarcar la importancia de la «actividad del sujeto», por la cual debe entenderse que no es adecuado definir rigidamente una secuencia de situaciones de aprendizaje por las que hayan de pasar los sujetos. Al contrario, debeh ser los propios sujetos los que vayan definiendo en cada momento su proceso de aprendizaje. En segundo lugar, los aprendizajes han de seguir la linea genética del desarrollo normal de la inteligencia. Finalmente, y complementariamente al principio anterior, tenemos la coordinación entre esquemas. La idea es que el uso de determinados esquemas, que son los únicos a disposición de los sujetos, lleva a conclusiones erróneas, pero que estos errores son necesarios y el sujeto es el único que puede convertirlos en tales y progresar así mediante nuevas coordinaciones entre esquemas hacia niveles evolutivos y nociones superiores. La información externa que califique de errores a estas conclusiones objetivamente erróneas, pero correctas para el nivel de inteligencia implicado, por ejemplo, la información proporcionada por el educador cuando el sujeto no es capaz de asimilarla, es fundamentalmente inútil e incorrecta.

El problema, a mi.entender, más grave con esta posición es que resulta difícil, sino imposible, encontrar las directrices, que permiten la determinación inequivoca de los esquemas necesarios, a coordinar entunces en tanto que subesquemas, 
para la constitución de una noción concreta. Una cosa es creer que la noción de número resulta de la coordinación de los esquemas correspondientes a la seriación y a la clasificación y otra deducir exactamente cuáles serian los esquemas correspondientes a trabajos como lectura, resolución de problemas, etcétera.

Precisamente este problema, reconocido por la mayoría de autores de la línea piagetiana no estrictamente ortodoxa o comprometida (Case, I978; Pascual-Leone et al., 1978), ha originado la busca de nuevos modelos que, manteniendo lo que podriamos llamar «espíritu» piagetano, incorporen unos mecanismos de predicción y verificación más afines a los métodos de la psicología experimental.

En esta línea, el modelo más importante $\mathrm{y}$, posiblemente, también más difundido sea la teoría de los operadores constructivos de Pascual-Leone (1979, I 977). Este modelo es realmente complejo y difícil de describir en forma resumida. Está formulado alrededor de tres principios generales: r) un principio de praxis asimiladora; 2) un principio de equilibración, y 3) un principio de organización psicológica a dos niveles. Case (1978) ofrece una descripción más clara y más directamente orientada al análisis de tareas. Este autor ofrece, además, un análisis de tareas de la noción de conservación de los liquidos que reproduzco a continuación para que el lector pueda comparar con los anteriores (ver página siguiente).

Otros análisis de tareas están tal vez menos comprometidos con modelos teóricos complejos y pretenden simplemente describir un algoritmo eficaz para la realización de un trabajo y/o verificar que el tal algoritmo es usado, efectivamente, por una población determinada. La tendencia cada día más común es la de incorporar los conceptos y modelos generados por la investigación en procesamiento de información.

Resnick y Ford (1978) presentan una serie de ejemplos para ilustrar la relación entre análisis de tareas y procesamiento de información. Uno de los modelos más generales intenta describir los componentes de un procedimiento para la solución de problemas que sea lo suficientemente generalizable como para poder ser considerado como una estrategia válida en el terreno del waprender a aprendern, tan en el centro en este tipo de investigación. A continuación figura el esquema del modelo. Los recuadros representan enunciados de dirección y los rombos decisiones ( $\mathrm{WM}=$ working memory $=$ memoria operativa; LTM=long term memory $=$ memoria a largo plazo) (ver página siguiente).

Quizá sean precisas unas palabras finales para excusar la longitud del presente apartado. Me ha parecido necesaria para ilustrar la entidad propia del análisis de tareas y el lugar privilegiado que ocupa de conexión con la psicologia experimental en general y cognitiva en particular.

\section{REQUISITOS}

La determinación de los requisitos para la entrada de unos sujetos particulares en un programa siempre incluye probablemente un elemento de decisión por conveniencia. Definidos los objetivos y elaborados los análisis de tareas, se trata de decidir cuáles de los componentes escogidos se exigirán al alumno antes de que éste inicie el programa. El nivel de los alumnos de la clase, la existencia o no de programas de trabajo para los requisitos, consideraciones de tiempo disponible y organización curricular son algunos de los determinantes prácticos de la decisión de ubicación del nivel de entrada al programa.

Es importante recordar y la aparente facilidad de lo expuesto en el párrafo anterior no nos ha de hacer olvidar, que la verificación de requisitos debe hacerse siempre, dado que un escaso o nulo éxito de un programa puede ser debido a la falta de estos requisitos en los alumnos. No considerarlo o no darle importancia llevaría a un sinfin de teorizaciones y modificaciones inútiles del programa. 
Clidoro 1

Modelo detallado de estrategia de exploración unidimensional (seguin Case, 1978)

Paso u operación

1. Exploración de la dimensión vertical del agua en el recipiente $\bar{A}$.
Esquemas especificos

(1) Esquema operativo de exploración de la extensión vertical de un objeto y registro de su punto elevado.

(2) Esquema figurativo representando el input visual del lado del recipiente $A$ mientras el ojo va explorándolo.

(1) Esquema operativo de exploración de la extensión vertical de un objeto, observando si sobrepasa el (aún visible) -punto más alto del objeto anterior.
2. Exploración de la dimensión vertical del agua en el recipiente $B$, observando que el agua en $B$ continúa más allá del punto donde llega en $A$.
3. Conclusión que el agua en $B$ es más alta que el agua en $A$.
(2) Esquema figurativo representando el «input» visual del recipiente B. Notar que, si la diferencia en altura no fuera inmediatamente clara, otro esquema tendria que ser conservado en este paso, representando la altura de A.

(1) Esquema operativo utilizando las diferencias percibidas en proyección vertical como «input» y generando una conclusión sobre cuál es la más elevada.

(2) Esquema figurativo representando la diferencia percibida en proyección vertical registrada en el paso 2 .

(1) Esquema operativo representando la regla: las cosas más altas contienen más.
Símbolo

¿ Exploración vertical.

G. A: lado.

$\because$ Exploración vertical.

- B: costado.

$\dot{\psi}$ Altura.

- Diferencia visual en extensión vertical.

¿ Más alto=más.
4. Conclusión de que hay más agua en $B$ que en
(2) Esquema figurativo representando la percepción generada en el paso 3; es decir, $B$ es más elevado que $A$.

\section{Evaluación inicial y final}

La evaluación final debe ser elaborada a continuación de la definición de objetivos. No ofrece dificultad si ésta ha sido hecha correctamente. Es importante hacerla antes de la aplicación del programa y no después porque en caso contrario es fácil caer en error de elaborarla más en función de esta aplicación, de las dificul- tades encontradas, de las respuestas dadas por los alumnos, etc., que de los objetivos, cuando son éstos los que cuentan en realidad.

La evaluación inicial ha de incluir una evaluación final o equivalente para asegurar que nó se va a enseñar algo ya alcanzado y una verificación de requisitos para asegurar el nivel de entrada de los alumnos. 
Grafos 5

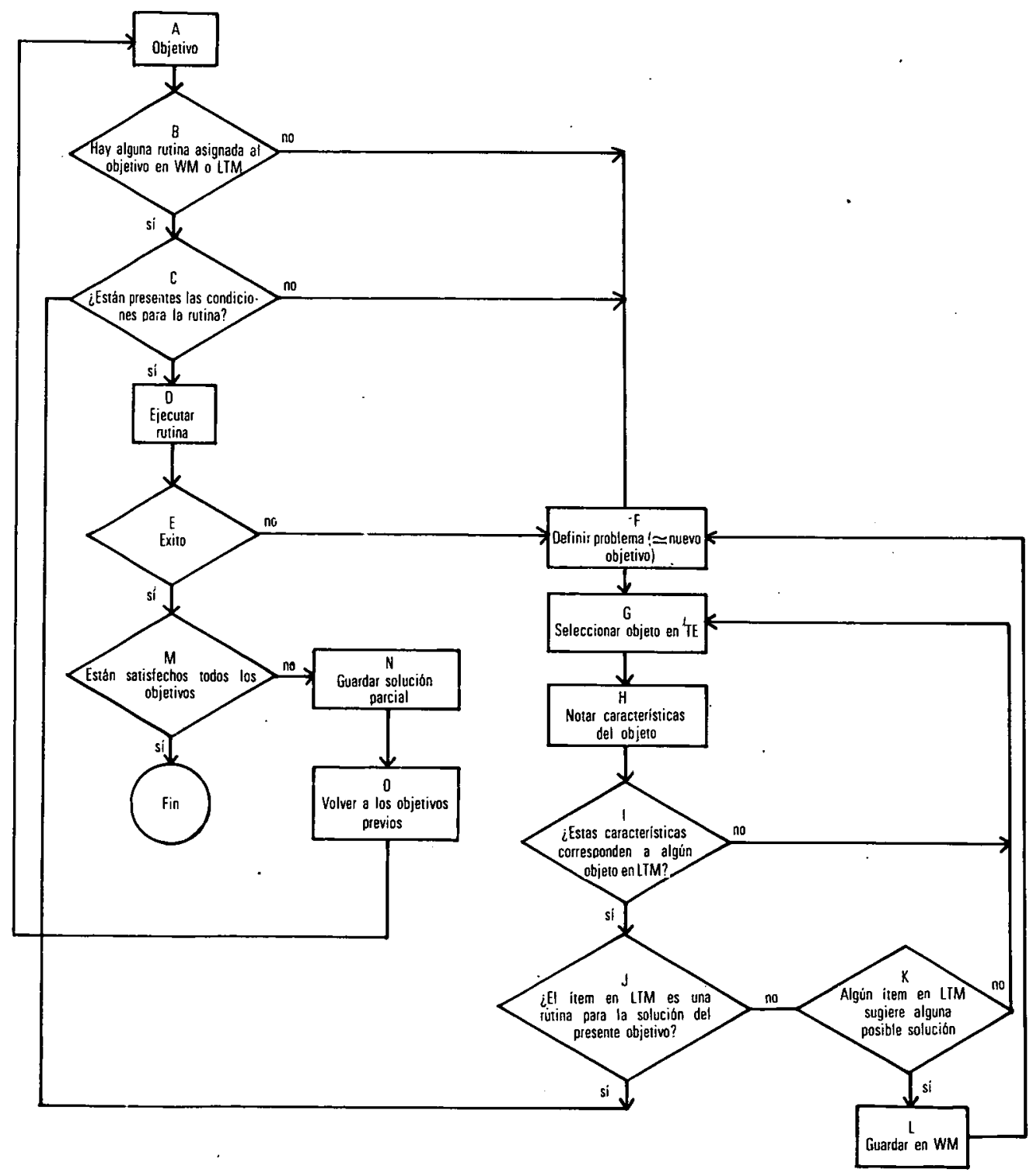

Un modelo para la solución de problemas de invención (Resnick y Ford, 1978). 


\section{Secuenciación}

Por convención, establecida en una de las reuniones del "Grupo», la secuenciación no se refiere, fundamentalmente, a la ordenación de objetivos. A cada objetivo le corresponde un cambio de programa. De esta forma, se diferencia entre diseño curricular $y$ diseño de programas. El primero no ha sido tratado aqui y sólo apuntado en la discusión sobre taxonomias de objetivos.

Dentro del diseño de programas, conviene contemplar los apartados que van siendo descritos. Sin salirse, empero, del marco de un programa, se hace precisa la secuenciación de las unidades de trabajo, ya sean estas fichas, lecciones o cualquier tipo de instancia de trabajo.

La secuenciación está estrechamente relacionada con el análisis de tareas, pero mantiene, no obstante, una personalidad propia. El análisis de tareas describe $\mathrm{cl}$ algoritmo de ejecución que seguirá un sujeto determinado una vez que haya alcanzado el objetivo y convertido en experto. La secuenciación indica el orden de adquisición de los componentes de la conducta terminal. Los dos ótdenes no tienen por qué coincidir. El ejemplo más claro es el encadenamiento inverso, en el cual el orden de adquisición es precisamente el contrario del orden de ejecución estipulado por el objetivo y el análisis de tareas.

Otra consideración es mucho más tentadora. Al menos, una intención que parece frecuente en el proceso de diseño de programas es la de obtener un programa en cuya implantación el alumno cometa pocos o ningún error. Esta idea de aprendizaje sin errores puede ser sometida a crítica desde la siguiente perspectiva: en una búsqueda sobre la inmunización contra la «desesperanza aprendida" (learned helplessness) en humanos, Jones, $\mathrm{Na}$ tion y Massad (1977) encontraron un efecto de inmunización utilizando un programa de reforzamiento del so por roo, pero no con programas de reforzamiento del o por 100 o del 100 por 100 , en tareas que eran, en definitiva, solución de problemas. En otras palabras, los sujetos inmunizados resistian sin desesperanza aprendida situaciones de contingencias aversivas (fracaso en la solución de los problemas) inescapables, mientras que los sujetos acostumbrados a un 100 por 100 de éxitos en la etapa previa caian en esta situación, al igual que los sujetos con una historia de fracaso absoluto (o por 100). Si comparamos la inmunización contra la desesperanza aprendida con la capacidad de enfrentarse con situaciones percibidas como muy dificiles sin desistir, parece que nos encontramos con un fenómeno interesante desde el punto de vista educativo.

Creo que vale la pena considerar, a partir de este tipo de evidencia, si en el diseño de programas y secuenciación no seria preciso decidir la inclusión de un determinado porcentaje de errores seguros. Una objeción que puede hacerse es la de que, a pesar de la intención de aprendizaje sin errores, los alumnos, y especialmente los alumnos deficientes mentales, cometen suficientes errores para eliminar la valía de estas consideraciones. Sin poder llegar a una conclusión definitiva, pienso, sin embargo, que el tema es interesante y que puede ser distinto un porcentaje de errores colocados estratégicamente que la producción espontánea de errores.

Establecida una secuenciación y probada en una implantación, existe la posibilidad interesante de proceder a verificar la corrección de esta secuenciación. Un procedimiento de resultados muy significativos y fácil de aplicar ha sido propuesto por Walbesser y Einsenberg (1972).

Se trata de considerar las unidades de una secuencia considerándolas de dos en dos consecutivamente. En la hipótesis de una buena secuenciación y si llamamos «a» a la unidad de nivel inferior y "b» a la unidad de nivel superior, hay que suponer: 1) la conducta "a" es imprescindible o condición necesaria de «b", y 2) que "a» más la instrucción prevista en el programa son condiciones suficientes de «b».

Es posible dar a estos supuestos una expresión cuantitativa de la siguiente forma: 
I. En primer lugar, es necesario ubicar a cada uno que han participado en el programa en uno de los siguientes grupos:

( $\mathrm{r}, \mathrm{I})$ : éxito en «b», éxito en «a».

$(\mathrm{I}, \mathrm{o})$ : éxito en «b», fracaso en "a».

$(0,1)$ : fracaso en «b», éxito en «a».

$(0,0)$ : fracaso en «b», fracaso en "a».

2. Con las frecuencias relativas a cada grupo, se puede proceder entonces al cálculo de los siguientes cocientes:

razón de consistencia:

$$
\frac{f(I, I)}{f(I, I)+f(I, O)}
$$

esta razón nos indica la media en que «b» implica a «a» o la medida en que «a» es, efectivamente, condición necesaria de «b» razón de adecuación:

$$
\frac{f(I, I)}{f(I, I)+(f \circ, I)}
$$

esta razón nos indica la medida en que «a» más la instrucción programada determinan «b», o la medida en que «a» más la instrucción son condiciones suficientes en «b».

razón de integridad:

$$
\frac{f(I, I)}{f(I, I)+f(0,0)}
$$

esta razón indica el porcentaje de sujetos capaces de atravesar la conexión «a», «b», investigada $y$, por tanto, ofrece información sobre la representatividad de los valores anteriores.

Walbesser considera válida una conexión cuando las razones correspondientes a la cual superan la puntuación de o,8 5 .

\section{Procedimiento}

El procedimiento describe la secuencia de demandas y respuestas, en definitiva, de interacciones, de las cuales se compondrá un acto didáctico (clase, sesión individual, etc.). En educación especial, donde hay una gama de recursos que no son tan utilizables como en otras situaciones, uno de los procedimientos más importantes es el uso de soportes. Un soporte es una ayuda externa que recibe el alumno, cuya disponibilidad no está previsto, sin embargo, en el objetivo final (si lo estu- viera sería una condición) y que debe ser retirado, por tanto, una vez cumplida su finalidad. Se pueden describir, en general, cuatro condiciones de aprendizaje en relación a los soportes usados:

I. Sin soporte: el alumno ha de dar la respuesta en las condiciones especificadas en el objetivo.

2. Soporte verbal: el educador instruye verbalmente al alumno sobre cuál es la respuesta adecuada. El soporte verbal puede ser oral 0 escrito, siendo obviamente más elemental el primero.

3. Demostración: el educador realiza lo que el alumno ha equivocado para que éste pueda repetirlo.

4. Soporte físico: en este caso, el educador ayuda directamente al alumno en la realización de un trabajo, acompañando su mano, etcétera. Es preciso notar que, en general, el soporte verbal acompaña siempe a las demostraciones y al uso del soporte físico.

Todo soporte debe ser retirado en el transcurso de la implantación del programa. Esta retirada se efectúa normalmente recorriendo los cuatro niveles de soporte en orden descendente. Una dificultad excesiva en el proceso de retirada debe ser investigada revisando los requisitos establecidos y el análisis de tareas efectuado.

Los que acabamos de describir son probablemente los recursos más importantes en educación especial. Para el estudio de otras posibilidades, mucho más sofisticadas o complejas, recomiendo al lector la obra citada de Fernández, Sarramona y Tarín (1977).

\section{Sistema de incentivos}

El sistema de incentivos más estudiado tanto experimentalmente como a nivel aplicado, fundamentalmente, por la modificación de conducta, es el control de contingencias. No es necesario probablemente repasar con mucho detalle los principios de refuerzo utilizados en este control de contingencias. Unicamente men- 
cionar las posibilidades de reforzamiento positivo y negativo y de castigo positivo y negativo y los dos principios de reforzamiento más utilizados que son el principio de Premack y el time-out. Reccrdemos también que el control de contingencias es solamente una cara de la moneda y que por si solo probablemente es insuficiente, debiendo ser complementado necesariamente por el control de estímulos (por ejemplo, Home et al., 1974).

Una extensión que va adquiriendo más importancia cada día y que ha surgido de la propia modificación de conducta es el conjunto de técnicas agrupadas bajo el nombre genérico de técnicas de autocontrol. El autocontrol implica usualmente la participación del propio sujeto en la contratación de las contingencias aplicables consecuentemente a trabajos realizados y la autoevaluación del trabajo hecho para determinar cuáles de las contingencias previstas en la contratación son aplicables. Esta evaluación puede no implicar únicamente el resultado final, sino el registro (monitoring) o autosupervisión de componentes de la ejecución previos a este resultado final: distribución en el tiempo del esfuerzo, calidad de la presentación, etcétera. Finalmente, remarquemos que es importante que, en lo posible, el reforzamiento sea apliçado por el propio sujeto (Craighead, Wilcoxon-Craighead y Meyers, 1978 ).

Hay otros recursos posibles que tienen función incentiva o modificadora, que no se basan en el control de contingencias. Una de las más inmediatamente aplicables posibilidades es la variación del canal de transmisión de información. Este parece ser, además, un factor especialmente importante para la motivación de niños autistas (Dunlap y Koegel, 1980).

Finalmente, es preciso decirlo, una buena relación entre educador y alumnos es fundamental en lo referente a la motivación de estos últimos en el proceso de aprendizaje. El valor de esta afirmación parece independiente del análisis teórico que quiera hacerse de esta relación.

\section{Material}

El material que se utilice en un progra- ma incorpora a éste un conjunto de características propias, que deben ser valoradas en la medida correcta.

Una distinción cotidiana e importante delimita ya dos tipos habituales de material: el que podriamos llamar «objetos reales» y el que podriamos llamar también "papel y lápiz». Desafortunadamente, yo, al menos, no conozco ningún estudio experimental serio que haya investigado con detalle las diversas características respectivas ni los usos más idóneos y distintos de estos dos tipos de material. Las ventajas intuitivas y prácticas del material de «papel y lápiz» consistirian principalmente en la facilidad con la que se presta a una secuenciación controlada $y$, por orra parte, hay contenidos que no pueden aprenderse sin él; especialmente en los niveles académicos ya algo adelantados es la base principal para la mayor parte de actividades. I.a objeción principal que puede hacerse a su uso abusivo es la de impedir una mejor variación en los canales de transmisión de la información utilizados, con un efecto desmotivador, y que en niveles bajos o en niños pequeños podria conducir a unos aprendizajes mal asimilados y poco generalizables a situaciones que implicasen, por ejemplo, objetos reales. Una posición a menudo enunciada y que en su expresión extrema parece exagerada afirmaría la primacia del uso de objetos reales sobre el papel y lápiz en el diseño curricular o de programas.

De los objetos reales se afirma usualmente que son más motivadores para los alumnos y que permiten o facilitan una mejor comprensión de los contenidos trabajados, suponiendo que requieren un menor grado de abstracción por parte de los alumnos que las representaciones gráficas de los mismos objetos. Aún cuando a nivel cotidiano parece evidente que el recurso a ambos tipos de material es necesario y más pronto complementario que antagónico, seria interesante disponer de información realmente rigurosa al respecto.

Otro tipo de material incluye la amplia categoría de los audiovisuales. Diapositivas, cassettes, películas y, ya más actual- 
mente, sistemas de vídeo son recursos con una cierta tradición de uso, que a mi me parece pueden estar siendo utilizados por debajo de sus posibilidades en educación especial. Esta opinión no está basada más que en una limitada experiencia personal.y es perfectamete posible que sea errónea o, al menos, incompleta. En todo caso sería interesante conocer aplicaciones concretas realizadas, dado que probablemente la educación especial sea un terreno en el que precisen usos distintos en alguna medida de los más habituales en eduación normal.

Mientras que los tipos de material nombrados hasta ahora son los tradicionalmente considerados en tecnología educativa, otro tipo de material está emergiendo de la generalización y abaratamiento de las tecnologías de alta electrónica y microcomputación, el cual merece, a mi entender, la más atenta consideración. Calcualadores manuales y miniordenadores, pero también muchos otros tipos de máquinas especialmente diseñadas para sujetos con dificultades especiales (máquinas de escribir, sillas de ruedas y otras que aparecen continuamente) son recursos importantes que han de afectar indefectiblemente $y$ en profundidad a todo el proceso educativo.

En un trabajo que también hemos presentado en estas jornadas, José Ferrer y yo mostramos los resultados positivos, aunque limitados, de una experiencia de uso de calculadoras en la resolución de problemas (Ferrer y Ortega, i $98 \mathrm{I}$ ), en la cual tres sujetos aprendieron a dividir empleando una calculadora y a usar la división al mismo nivel de corrección que la suma, dominada a nivel manual. Creo que valdría la pena plantearse seriamente la posibilidad de introducción de las cuatro operaciones básicas mediante calculadoras tan pronto los minimos requisitos de numeración estuviesen cubiertos.

Otra posibilidad importantísima que ha de llegar a ser en el futuro la base del trabajo educativo en sujetos afectados de muy diversos tipos de impedimentos motrices, paralíticos cerebrales, sordos, ciegos, etc., es el desarrollo y aplicación de técnicas de bio-feedback específicos para los problemas de estos sujetos. Esta linea de trabajo está dando los primeros, aunque tentativos pasos (Goldenberg, 1979; Walton, i 979).

lgualmente, el uso de aparatos especialmente diseñados para sujetos con dificultades específicas ha de permitir la normalización de sus posibilidades de autonomía, en forma quizá semejante a como un útil tan cotidiano como las gafas normalicen a personas que sin ellas no tendrian la más mínima posibilidad de autonomía en nuestra sociedad.

Finalmente, el uso de ordenadores permitirä, con toda seguridad, unos niveles de control, individualización de la enseñanza $y$, especialmente, inmediatez y continuidad en la administración de contingencias imposibles de alcanzar en la actualidad (Goldenberg; 1979).

\section{Sistema de registro}

Los sistemas de registro deben permitir la recogida de información relevante en el transcurso de la implantación del programa. Un buen registro tiene las siguientes finalidades principales: I) el control ajustado del progreso del alumno; 2) el asegurar que éste no se vea confrontado innecesariamente con tareas que ya tiene superados, y 3) el permitir verificar la corrección de la secuenciación.

En efecto, debe evitarse que un alumno permanezca más tiempo del previsto o del necesario en un mismo nivel de trabajo cuando ya lo ha superado. Pero también, igualmente, si a pesar de haber recorrido sin problemas una parte del programa, un alumno se para en un punto determinado, el registro es lo único que nos permitirá localizar con precisión el punto donde hay probablemente un error de secuenciación.

En la práctica, nos ha resultado conveniente distinguir entre dos tipos de registro: registros de programas en los que se supone que el alumno únicamente debe hacer concretamente una vez una unidad de trabajo determinado para poder pasar a la siguiente y registros de programas en los cuales se supone que el alumno ha de 
realizar múltiples veces el mismo trabajo, aunque simultaneamente esté haciendo otros semejantes. Un ejemplo del primer caso sería un programa de lectura y del segundo uno de escritura.

En las dos páginas siguientes tenemos un modelo de tipos de registro utilizado en cada caso. El primero se utiliza simplemente colocando en el recuadro de la primera columna el número de orden de la ficha trabajada y en el recuadro siguiente, en la segunda columna, la respuesta dada, según cualquier codificación convenida y diferenciando respuesta correcta, incorrecta, aproximada y respuesta nula. Dispone también de un espacio para anotar la fecha.

El segundo se utiliza de forma diferente: Cada columna del i al 40 , corresponde a una jornada de trabajo. Se marcan los números correspondientes a las fichas trabajadas según la codificación: $O$, respuesta correcta; $\mathrm{X}$, respuesta incorrecta; 1, respuesta aproximada. En la linea de puntos situada en el espacio inferior se anota la fecha. De esta forma, en columna se lee el trabajo efectuado en una jornada $y$ en fila el número de veces que el alumno. ha hecho la misma ficha.

\section{Sujetos}

Actualmente asistimos a una etapa de cambio y fuerte controversia sobre la forma de evaluar las caracteristicas de los alumnos que pueden ser relevantes para su ubicación en programas, grupos, escuelas, etc. A los tests psicométricos tradicionales, a menudo durante criticados, se han unido los "tests referidos a criterios" (criterion referenced tests), en los cuales los ítems están relacionados con objetivos definidos explícitamente y donde las puntuaciones son interpretadas en términos de estos objetivos más que en relación a los parámetros de una población.

Antes de comentar con más detalle esta cuestión, es preciso delimitar con precisión las diferencias entre los dos sistemas. A mi entender, éstas pueden reducirse a dos:
1) Los ítems en los tests psicométricos son escogidos normalmente por la saturación que presentan en un determinado factor que es el que quiere medirse. Recordemos que un factor es solamente un grupo de medidas que varian conjuntamente en la proporción indicada por su saturación respectiva (Vernon, 196I). Los ítems en los tests referidos a normas o criterios son escogidos como representativos del sistema curricular que se quiere evaluar. Este sistema curricular tiene la justificación y sentido de cualquier programa académico.

2) I.as puntuaciones en los tests psicométricos se interpretan en términos de puntuaciones típicas, es decir, referidas a los parámetros de la. población de referencia. Si las puntuaciones típicas se estructuran con $\overline{\mathrm{x}}=\mathrm{I} 00$ y $\delta=\mathrm{I}$, nos encontramos con el C. I. (aunque en realidad ya no son cocientes como en las escalas de Binet, por ejemplo). Las puntuaciones en los tests referidos a criterios indican simplemente el nivel alcanzado por el sujeto.

En la práctica, empero, los tests referidos a criterios también indican de alguna forma el nivel de retraso del sujeto indicando el porcentaje de items alcanzando a una edad determinada (esto hace, por ejemplo, el U. P. A. S., White et al. 1978). De esta forma, la segunda distinción parece que quede reducida a una cuestión de procedimiento más que a una cuestión conceptual: o no se compara a un sujeto a ningún nivel standard, con lo cual no podemos saber su nivel de retraso, o simplemente escogemos entre compararlo con una población de referencia a través del porcentaje de items alcanzados en una edad determinada o a través de la tipificación de puntuaciones. $\mathrm{Y}$, en $\mathrm{mi}$ opinión, el segundo procedimiento tiene la ventaja de incluir las desviaciones tipicas, con lo cual se obtiene en principio más precisión en la comparación. 

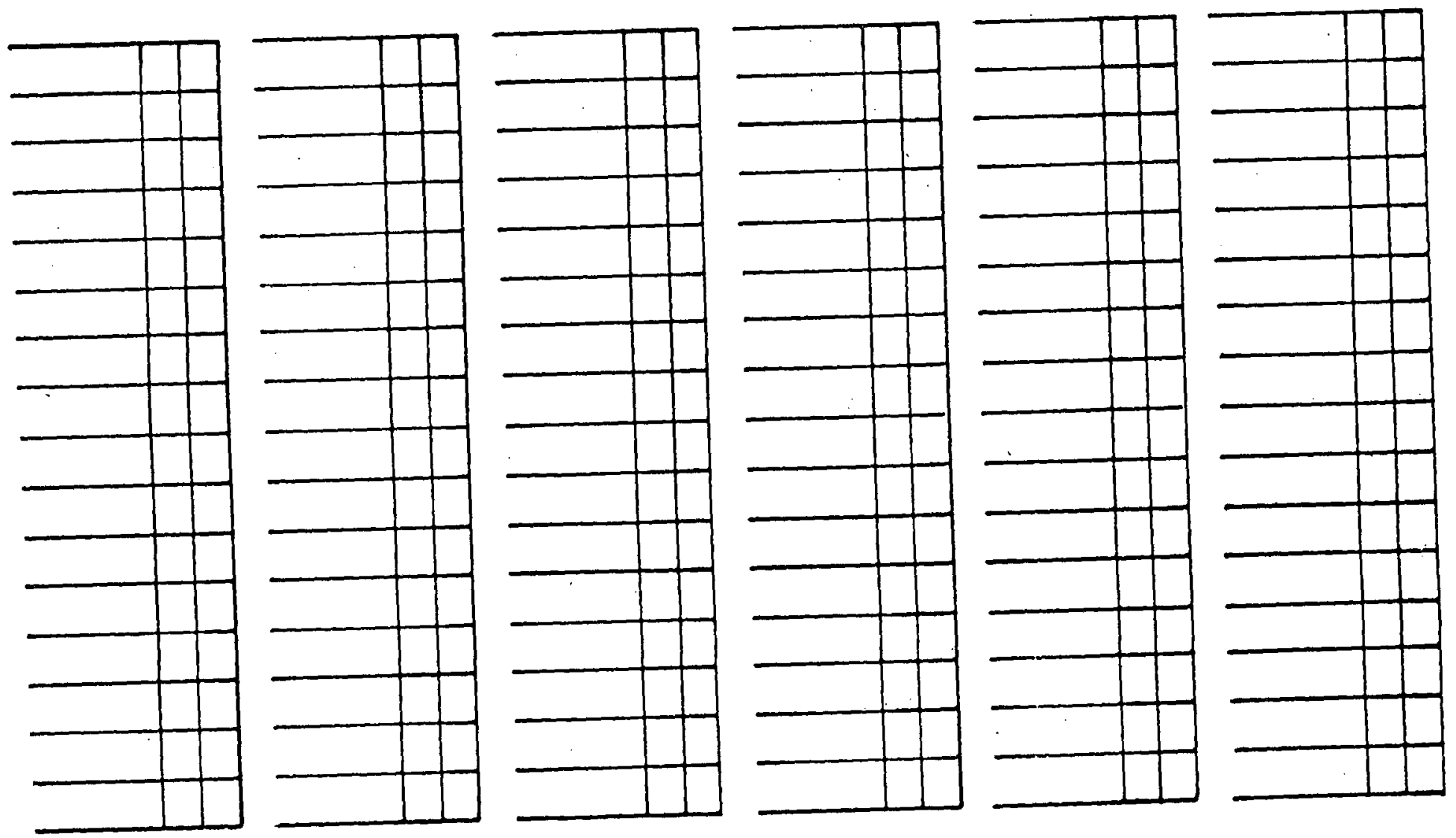


\section{Sujeto:}

Programa:

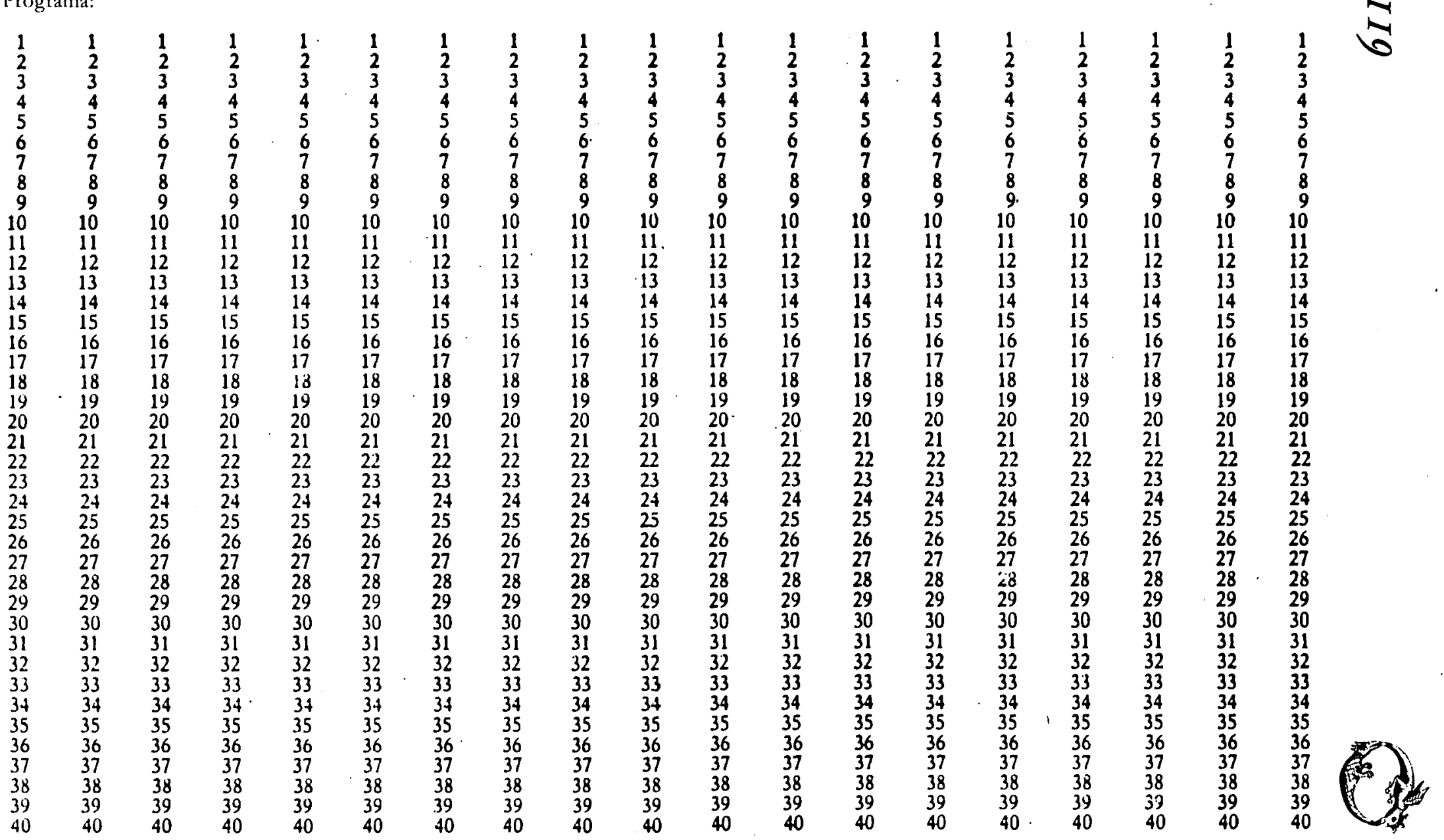

E. 
Respecto a la primera distinción, tampoco me parece que sea tan concluyente. El análisis factorial en concreto se puede aplicar a cualquier dominio y sería quizá interesante verificar las clasificaciones intuitivas en áteas y subáreas (lenguaje, social, cognitiva, etc.) de los items mediante un análisis factorial.

La conclusión que justifica esta larga exposición es la de recuperar algo el valor de los instrumentos más tradicionales como son los tests psicométricos y la de, al aceptar el interés de los tests referidos a criterios, exponer algunas posibles lineas de desarrollo convergente más que antagónico.

En definitiva, al describir, por ejemplo, la población con la cual se ha trabajado un programa, creo que es necesario especificar el nivel de los sujetos en términos de C. I. Otras precisiones son también importantes: etiología médica, tipos de trastornos (autismo, deficiencia mental, parálisis cerebral, etc.). La única forma de ver la importancia de estas categorías es contrastarlas empíricamente con resultados, pero las que hemos expuesto pueden darse ya con seguridad por verificadas.

\section{Referencias}

Bender, M.; Valletutti, P. J.: Teaching The Severely And Moderately Handicapped, vol. I, II i III. Baltimore: University Park Press, 1976.

BertalanfFy, L.: The Theory Of Open Systems In Phisics and Biology. En F. E. Emery (ed.): Systems Thinking. Harmondsworth, Middlesex: Penguin Books, 1969, 70-85.

BLoOM, B. S. et al.: Taxonomia de los objetivos de la educación. Buenos Aires: El Ateneo, I 97 I.

CASE, R.: Piaget and Beyond: «Towards a Developmentally Based Theory and Technology of Instruction.» En R. GLASER (ed.): Advances in Instructional Psychology. Hillsdale, New Jersey: LEA, $197^{8}, 167^{-228}$.

Craighead, W. E.; Wilcoxon-Craighead, L.; MEYers, W.: «New Directions in Behavior Modification with Children.» En M. Hersen, R. M. Eisler i P. M. Miller (eds.): Progress in Behavior Modification, vol 6. New York: Academic Press, 1978, 159-201.

Dunlap, G.; KoEgel, R. L.: Motivating Autistic Children Through Stimulus Variation. J.A.B.A., vol. 13, n.o $4,1980,619-627$.

Ferrández, A.; Sarramona, J.; TARín, L.: Tecnologia Didáctica: Teoria y práctica de. la Programación Escolar. Barcelona: Ed. CEAC, 1977.

FisRriar, J.; ORtega, J. LI..: Resolucio de problemes $i$ is de la calculadora. Treball presentat en la I. ${ }^{a}$ Trobada del "Grup d'Investigació en Educació Especial», 1981 .

GAGNE, R. M.: Las condiciones del aprendizaje. Madrid: Ed. Aguilar, $197^{\circ}$.

GAGNF, R. M.: "Contribuciones del aprendizaje al desarrollo humano», en J. Delval (ed.): Lecturas de psicologia del niño, vol 2. Madrid: Alianza Editorial, 1978.

GaGne, R. M.; BEARD, J. G.: Assessment of Learning Outcomes. En R. Claser (ed.): Advances in Instructional Psychology. Hillsdale, New Jersey: LEA, 1978, $261-294$.

GlASER, R.: «Components of the Instrutional Process.» En J. P. De Cecco (ed.): Educational Technology: Readings in Programmed Instruction. New York: Holt, Renehart Winston, $1964,68-76$.

GoldenberG, E. P.: Special Technology for Special Children. Baltimore: University Park Press, 1979.

Home, Ll. et al.: "Qué es la ingeniería conductual.» En R. Ulrich, Th. Stachnik i J. Mabry (ed.): Control de la conducta bumana, vol. 2. México: Ed. Trillas, 1974, 40-49.

Howe, A.: Introduction. En A. Howe (ed.): International Yearbook of Educational and Instructional Tecbnology 1980/81. London: Kogan Page Ltd., 1980, 9-1 3.

InHelder, B.; Sinclair, H.; Bovet, M.: Apprentisage et Structures de la Connaissance. París: P.U.F., 1974 .

jones, L. J.; NATION, J. R.; Massad, Pll.: «Immunization Against Learned Helplessness in Man». Journal of abnormal Psychology, 1977, vol. 86, n.0 I, $75-83$.

KATZ, D.; KAHN, R. L.: «Common Characteristics of Open Systems». En F. E. Emery (ed.): Systems Thinking. Harmondsworth, Middlesex: Penguin Books, 1969, 86-104.

KaUfMAN, R.: Planificación de sistemas educativos. México: Ed. Trillas, i 973.

KaufMan, R.: «Needs Assessment». What Is It and How to Do It. San Diego, Ca: United States International University, UCIDT, 1975 . 
Kaufman, R.: "The Passion for the Practical: Are Educational Technologists Losing Their Idealism?" Educational Technology, January 1980, 22-28.

KAUfman, R.: «Achieving Useful Results: Beyond Performance and Instruction». NSPI Journal, December 1979, 4-8.

KAUfMAN, R.; STUNE, B.: "Possible Research Directions for the Improvement of Learning". Improving Human Perfomance Quaterly, vol. 8, n. ${ }^{\circ}$ 2, 80-86.

KOzLOFF, M. A.: Educating Children with Learning and Bebavior Problems. New York: J. Wiley \& Sons, 1974 .

MAGER, R. F.: Preparing Instructional Objectives. Belmont, Calif.: Fearon, 1962.

Mil.teR, J. G.: "The Nature of Living Systems». Bebavioral Science, 1971, 16, 277-301.

Moreno, M.; SASTRE, G.: "Evolución de las deficiencias intelectuales sometidas a un aprendizaje operatorio». Anuario de Psicologia, n.o 4 , 197 I (1), 71-146.

PASCUAl-Li:ONL:, J. et al.: «Piagetian Theory and Neo-Piagatian Analysis as Psychological Guice of Piaget's Work and a Critique of Information-Processing Simulation Psychology». En H. Spada i R. Kluwe (eds.): Developmental Models of Thinking, New York: Academic Press (1977).

Pascuat-Lrione, J. et al.: Piagetian Theory and Neo-Piagetian Analysis as Psychological Guides in Education. En J. Mac Carthy Collagher i J. A. Easley (eds.): Knowledger and Development, vol. 2. Plenum Publishing Corporation, 1978, 243-289.

Pascual-Leone, J.; GoOdman, D.: Intelligence and Experience: A Neo-Piagetian Approach. York University, Departament of Psychology Reports, Report n.0 $8 \mathrm{I}, 1979$.

RESNICK, L. B.; FORD, W. W.: "The Analysis of Tasks for Instruction: An Information-Processing Approach". En A. Ch. Catania i Th. Brigham (eds.): Handbook of Applied Behavior Analysis. New York: J. Wiley Sons, 1978, 378-409.

RIBES INEST A. E.: Técnicas de modificación de conducta: su aplicación al retardo en el desarrollo. México: Ed. Trillas, 1972.

SIMON, H. A.: «Information-Processing Models of Cognition». En M. R. Rosenzweig i L. W. Porter (eds.): Annual Review of Psychology, vol. 30, 1979, 363-396.

SundberG, N. D.; Tyler, L. E.; TAPLIN, J. R.: Clinical Psychology: Expanding Horizons. New York: Appleton-Century-Crofts, 1973.

TARIN, L.; Llacuna, J.: El enfoque sistemático del proceso de enseñanza. Ministerio de Trabajo, Dirección General de Servicios Sociales: Servicio de Higiene y Seguridad en el Trabajo, 1976.

Trimby, M. J.: Needs Assessment Models: A Comparison. Articulo aparecido en Educational Technology, 1979 .

WAlBESSER, H. H.; EISENBERG, T.: A Keview of Research in Behavior all Objectives and Learning Hierarchies. Citado por J. D. McGregor: A Comparison of White's and Walbesser's Learning Hierarcby Validation Techniques. ED $174,623,1978$.

WALTON, W. T.: The Future of Biofeedback Training in the Field Special Education. ED I 7 I, 060, 1979.

White, O.; EDGar, E.; HaRING, N. G.: Uniform Performance Assessment System. University of Washington, 1978 . 